\title{
Applying Social Capital and SECI Model to Explore Gender Differences in Knowledge Sharing Behaviors
}

\author{
Ying Chieh Liu \\ Department of Information Management \\ Chaoyang University of Technology, Taichung, Taiwan
}

\begin{abstract}
Little has been known in the understanding of how gender differences in knowledge sharing in a virtual team context. This study forms a framework by incorporating social capital and SECI model and examines it by an experiment with 65 student virtual teams collaborating in a Wiki platform. The results show that the only difference across gender is the significant path from socialization to performance for female. This study also confirms that social capital has significant impacts on knowledge sharing for both genders and knowledge sharing has a significant impact on virtual team performance.
\end{abstract}

\section{Introduction}

The existence of biological differences between genders has led to a tendency to assume that other observed differences between males and females are due to biological determinates. Essentialism theory [21] attributes that the behavioral differences across genders to what are believed to be inherent, fixed, group-level differences are based upon biopsychological characteristics. An inference can be drawn from this perspective is that males and females should behave differently in a virtual environment. However, little research has addressed the gender differences in knowledge sharing in a virtual team context. This study forms a framework to formulate the behaviors of knowledge sharing and further identifies the gender differences. The purpose of this study is to provide a more detailed understanding of gender differences in knowledge sharing behaviors and their impacts on virtual team performance in a perspective of social capital.

\section{Model development}

Social capital is conceptualized into three facets: structural capital, cognitive capital and relational capital. It considers that the resources and information in our life are transmitted through the social network, and it believes that the retrieval of the resources and information owned by individuals or groups depends on the establishment and maintenance of social relationships. Thus, accessing to social capital relies on social connections, such as engaging in social activities, maintaining common hobbies as well as building trust.

Knowledge sharing has been identified as a major issue for knowledge management and an important factor for evaluating the performance of organizations [7]. Most scholars have focused on knowledge sharing in the context of organization and community. Little research has been made to explore how virtual team members sharing their knowledge and how knowledge sharing effects their performance. The SECI model by Nonaka [13] has been identified as the most outstanding work in knowledge management. In his model, possession, transformation and delivery of knowledge are significant attributes to handle. This study formulates knowledge sharing by the four behaviors from the SECI model: socialization, externalization, combination and internalization. Socialization is a mode of converting tacit knowledge through interaction between individuals and is a process of transferring implicit knowledge into implicit knowledge such as a shared mental model and common skills. Individuals are able to retrieve implicit knowledge by observation, imitation and practice, instead of through dialogue. Combination is a mode that involves the use of social processes to combine different bodies of explicit knowledge held by individuals. It is a process of categorizing, reclassifying and synthesizing to creating a new format of explicit knowledge. Externalization refers to the conversion of tacit knowledge into explicit knowledge by metaphor, analog, hypothesis and model; while internalization relates to the conversion of explicit knowledge into tacit knowledge by practice or re-experience. 


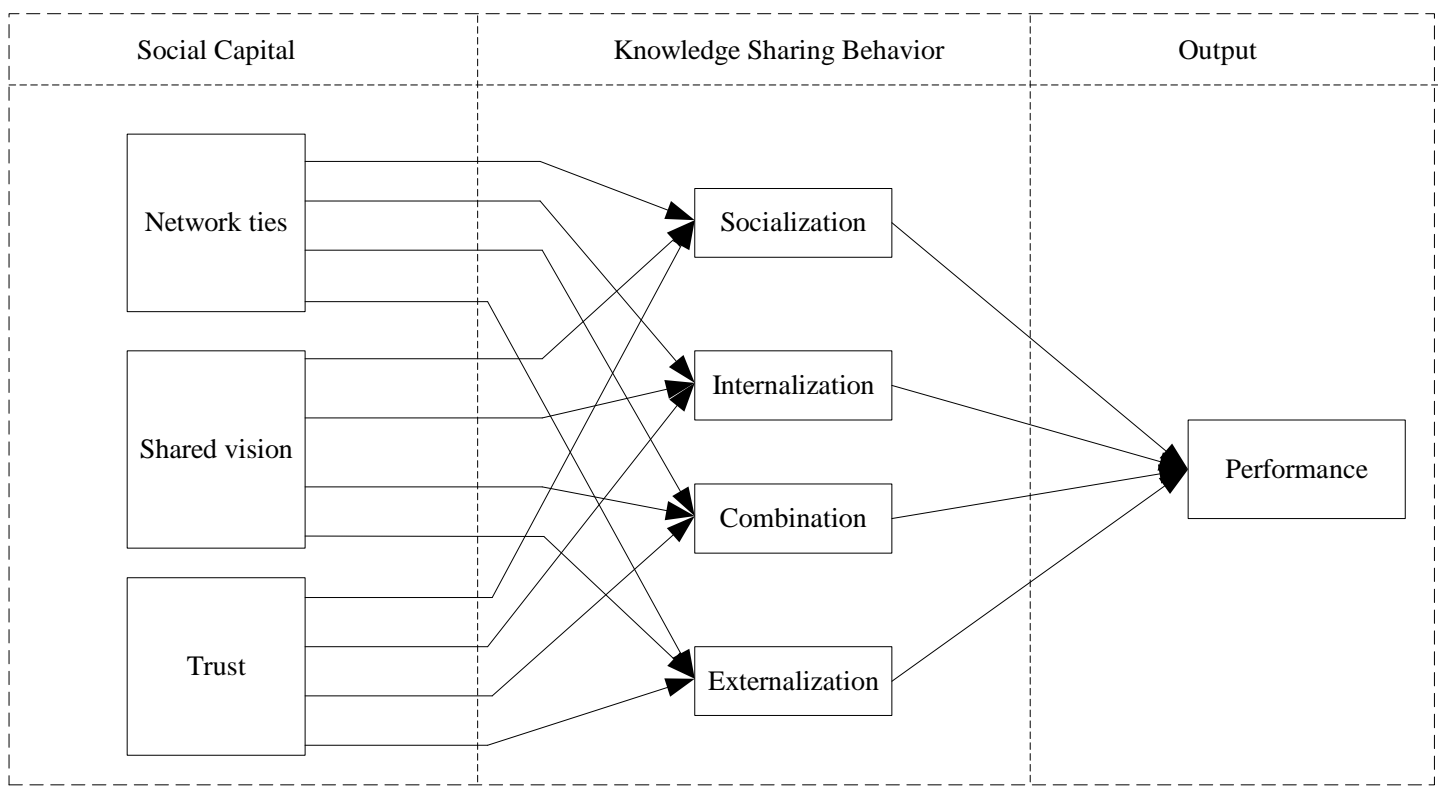

Figure 1. The proposed model

Past studies suggested that social capital is associated with knowledge sharing (e.g., [19][24]). As in a virtual environment, CMC (ComputerMediated Communication) plays a role of connecting members who are dispersed geographically to build social ties and promote knowledge sharing. Social capital presents the inlay of suitable personal relationships and integrity of social network. When networks are dense and comprise a great deal of proportion of string and direct network ties between members, the knowledge sharing would be easier to achieve [22].

This study presumes that social capital (network ties, shared vision, trust) positively related to the four modes of SECI [13]: socialization, combination, externalization and internalization. Virtual team members rely on the electronic messages to convey their ideas to address the common challenges. During this process, members have to firstly express their ideas by converting tacit knowledge into implicit knowledge, and then transfer to other members (externalization). When other members receive the messages, they have to absorb, embody and convert them into individually held tacit knowledge (internalization) or synthesize existing explicit knowledge to construct a new knowledge (combination). Although there is lack of face-to-face meetings and discussions, the tacit knowledge owned by an individual is disseminated within the team (socialization). Social capital promotes the process of distribution of knowledge and knowledge creation. The model is drawn in Figure 1.

\subsection{Network ties}

The three stages of knowledge assimilation (stage one: exploring the ontology of a familiar concept; stage two: mapping to a new concept; and stage three: assimilation) explain how one constructs his own knowledge from the adaptation of new knowledge transferred by others [18]. Knowledge assimilation includes not only knowledge transferring but also personal adaptation and social adjustment, which refers to the phenomena of embracing others' beliefs and assimilating into the teams. However, knowledge assimilation relies on effective links among knowledge entities called network ties here. An empirical study by Morrison [11] found that the strength of social ties provide the support of social integration and commitment. Knowledge assimilation could be promoted in a setting with high commitment and social integration. Thus, we assume that network ties are positively related to socialization.

Internalization and combination are the processes of creating new knowledge, which can be called "kaleidoscope thinking", meaning the construction of knowledge from the available fragmental data and turning them into new knowledge. Knowledge created by internalization can be conceived as visceral knowledge [17], which is richly grounded in professional know-how and pertains to the absorption of old knowledge to create new knowledge internally. In a virtual team context, knowledge is created upon the interaction of individual knowledge, experience and intimate knowledge received from other team members. Combination refers to the actions of collecting, editing, sorting and synthesizing the documenting 
knowledge explicitly. Such behaviors include the processes of exchanging ideas between virtual team members and the operations of computer technologies, such as Word and Excel. Network ties ensure the occurrence of kaleidoscope thinking in two ways. Firstly, network ties provide channels for members to exchange information. The more information is transmitted, the more combination actions will be. Secondly, strong network ties promote the socio-emotional support that creates bonding between members. This would raise a sense of goodwill and further encourage the absorption and transformation of knowledge derived from others [12]. Thus, we assume that network ties are positively related to internalization and combination.

Externalization refers to the conversion of tacit knowledge into explicit knowledge. Hendriks [7] found that strong network ties guaranteed higher frequency of communication intention. Wasko and Faraj [22] also found that people had greater intention to contribute their knowledge when they were structurally embedded in a network with strong ties. Therefore, it can be inferred that network ties affect members' inclination of transforming tacit knowledge into explicit knowledge for sharing with other members. Accordingly we assume that network ties are positively related to externalization.

\subsection{Shared vision}

When members have the same perceptions of how to interact with others, there is a higher possibility to avoid misunderstanding in their communications and to achieve higher degree of tolerance for mistakes [16]. Shared vision helps members develop a common mental model and lead the team toward the correct direction. Additionally, Yli-Renko et al. [24] explained that shared vision encourages relative absorptive capacity, which is the ability to absorb new knowledge. This ability relies on one's possession of prior, related knowledge. Due to the ability to absorb the communicated knowledge is improved through continual social interactions, members have relatively greater incentives to contribute more in knowledge-sharing routines. By intensifying the transmission of tacit knowledge from one member to others, shared vision serves to increase the relative absorptive capacity and form common mental models. Thus, we assume that shared vision is positively related to socialization.

Researchers examined the relationships between shared vision and knowledge transfer and found that shared vision is positively correlated with knowledge sharing and transfer (e.g., [3]). Shared vision helps convey a sense of identity and create commitment between members. It also inspires members to strive for the collective goals. Therefore, the sense of participation would be higher when virtual team members share the same vision, which in turn acts as a resource influencing both the anticipation of value to be achieved through cooperation and the motive to share their knowledge by transforming tacit knowledge into explicit knowledge, and combining all sort of explicit knowledge to form new knowledge. Thus, we assume that shared vision is positively related to combination and externalization.

A lack of shared vision becomes especially problematic when considering the internal transfer of knowledge. To achieve the team goals, members need to exchange all sorts of knowledge to fill in their knowledge gaps in order to develop better solutions. Knowledge complementarity is realized by receiving inflow knowledge from others and it is absorbed to construct mental models. Higher level of shared vision may act as a catalyzer forcing members to accept the fragmental data and turn them into their tacit knowledge. Thus, we assume that shared vision is positively related to internalization.

\subsection{Trust}

Trust refers to the faith in trustworthy intentions of members and the confidence in the ability of others, yielding ascriptions of capability and reliability [15]. According to Politis [15], both confidence and faith are positively related to communication and problem understanding. This study implies that trust encourages members to exchange more information and ideas, and it may facilitate knowledge assimilation. Therefore, it can be assumed that trust reinforces faith and confidence toward other members, and further supports knowledge assimilation. Thus, we hypothesize that trust is positively related to socialization.

Scholars have found that trust can enhance the ability to absorb new knowledge and facilitate knowledge transfer (e.g., [4]). Probst et al. [16] explained that trust is capable of forming an atmosphere of tolerating mistakes made by others, which fosters the culture of knowledge creation. On the other hand, if distrust is present, knowledge generation will be hindered, as fear, cynicism and wariness would prevent an individual from sharing required knowledge or information with other members. Thus, the author believes that trust can enhance the degree of relying on other members to improve the absorptive capability. Thus, we assume that trust is positively related to internalization.

Trust is an important catalyst to motivate members to exchange information and ideas. Trust also fosters people's willingness to help others and hope things go well in the team. The actions for sharing knowledge include documenting the knowledge residing in their mind, and manipulating, editing and synthesizing the explicit knowledge. Thus, trust is regarded as a facilitator to promote people in archiving their tacit knowledge into explicit knowledge and integrating documented 
knowledge as new knowledge. Accordingly, we assume that trust is positively related to combination and externalization.

\subsection{SECI vs. performance}

The author proposes that the idea of socialization is positively related to virtual team performance. The stimulation of a variety of sparks and the coalescence of these sparks into solutions of virtual teams are requisite. Each skilled individual frames both the problems and solutions by applying the knowledge he or she understands best when a virtual team addresses the common challenges. The creative abrasion may rise due to the cacophony, which leads to the process loss. However, idea convergence is needed and happens by dialogue between members where thoughts are exchanged informally and built on informal network. This informal network refers not only to building relationships but also exchanging tacit knowledge. Therefore, it is believed that more socialization activities cause more process gain and it further improves virtual team performance. Thus, we assume that socialization is positively related to virtual team performance.

Knowledge created by internalization includes a vivid image of how the problems are and the nuances of how the different solutions fit the problems. Individuals acquire intimate knowledge which is grounded in professional know-how to conceive methods by discussing through CMC. Internalization entails the trial-and-error exercises to gain a deep comprehension of reasoning or functioning solutions. By internalization, the solutions are developed from discussions and information exchanged. More internalization activities are more ideas and better solutions may be created, which cope better with the problems. Thus, we assume that internalization is positively related to virtual team performance.

Schulze and Hoegl [17] found that combination is negatively related to the novelty of product ideas. However, this study proposes the opposite idea in a virtual team context. Collecting, editing, sorting and synthesizing explicit knowledge into systematical knowledge are important steps for virtual teams when tackling problems. In a virtual environment, CMC is the only channel to exchange information. Except text-based communication (discussion board or online chatting), the knowledge is packed as a file format, such as Word, Excel and picture. Here, better ideas and more solutions are formed by referring to existing, visible explicit knowledge, rather than to imaginary tacit knowledge. Thus, we assume that combination is positively related to virtual team performance.

Schulze and Hoegl [17] proved that externalization is negatively related to the generation of novel product ideas. This study proposes the contrary idea that externalization is positively related to virtual team performance. Externalization is a continuous act that appears in the entire life expectancy of virtual teams. The format of externalization can be discussion discourse and files, and externalization forms a necessary channel for other members to receive information to improve their own knowledge. Hence, it is believed that more externalization activity is more information exchanged. According to the Media Richness Theory, uncertainty and equivocality would be reduced if more information is exchanged, which leads to the success of virtual teams. Thus, we assume that externalization is positively related to virtual team performance.

\section{Gender differences}

Research has found that females agreed more often, asked more questions, challenged others less often and qualified other's arguments less often than males [10]. Gender has been correlated with prestige and accompanied by differing expectations for males and females' social power. Males and females perceived differences in the amounts of respect, influence and prominence, which may affect their behaviors and attitudes in groups. O'Farrell and Harlan [14] reported that females who were working in a male-dominated environment were subject to harassment. Such as female police officers experienced disadvantage in their jobs while they were working in a male-dominated environment. Furthermore, males are more sensitive than females to be in the minority because males have historically been in the majority and enjoyed higher position in a group. Thus, males may perceive being in the minority as a power loss but females with more experience located in lower position or as numerical minorities do not [20]. These studies presented the substantial heterology between males and females.

\subsection{Gender in group outcomes}

It is also found that the asymmetry of team composition in gender affects group outcomes. Males respond more negatively, being absent more often, behave less committed than did females when they are in the numerical minority in a group [20]. Males also show the tendency of sexism when they are in male-dominated groups while females maintain more egalitarianism regardless of the sex composition.

The Similarity-attraction paradigm [2] suggests that people are attracted to and prefer to spend time with partners who have similar attitudes. Drawing on this logic, people who are more similar to a group are more likely to present higher commitment and lower turnover [23]. Males appear to be more sensitive to being different than females, which implies males respond with more negative attitudes than do females 
when group heterogeneity increases. In summary, males are attracted to work in groups with more males while females are attracted to work in groups with more females.

The Social Construction of Reality [1] argued that all knowledge is derived from and maintained by social interactions. When people interact, they do so with the understanding that their respective perceptions of reality are related, and as they act upon this understanding their common knowledge of reality becomes reinforced. Since this common sense knowledge is negotiated by people, human typifications, significations and institutions come to be presented as part of an objective reality. It is in this sense that it can be said that reality is socially constructed. This theory's implication toward this study is that group outcome comes from the interactions of virtual team members, which infers the virtual team members need to agree certain conventional rules or norm being a team to accomplish the tasks.

Virtual team members work based on CMC such as e-mail, discussion board, Blog, video and voice conference, as they often communicate asynchronously in accomplishing their jobs. This type of collaboration enables them to be uninhibited in the obstacles of distance and different time zones. However, recent studies have highlighted a rising phenomenon: females prefer working in a virtual environment and have higher extent of satisfaction than males. For example, Lind [8] found that females showed higher tendency of greater task analyzability, less task variety and greater information equivocality in email usage. Another study by Gefen and Straub [6] proved that females perceived higher social presence and usefulness for CMC technology. Thus, we hypothesize that females and males have different knowledge sharing behaviors in a perspective of social capital.

Hypothesis: Females and males have different knowledge sharing behaviors in a perspective of social capital.

\section{Research design}

Students from seven classes in three universities which were located in three dispersed counties in Taiwan were required to complete a case study as their final assignments. The project operated over five weeks. Students were chosen randomly from each class and were put into a group with four or five members. Female students $(\mathrm{n}=128)$ and male students $(n=174)$ were distributed equally to groups. This brought 65 groups comprised of 302 students in total. Each group was pre-assigned to their Wiki working space and had to access their discussion boards to discuss and exchange information to complete the assignments. Students were only allowed to communicate members via the provided Wiki system. After completing the assignments, hard copy questionnaires were distributed in the lectures. Participants were asked to use a 7-point Likert scale in answering the questions related to the framework. 287 validated questionnaires were collected, giving a return rate of $95 \%$. The female group comprised of 125 participants while the male group comprised of 162 participants.

\subsection{Measurement items}

The measurement items for the eight constructs were derived from past studies. All items were reviewed and revised to fit this study. The measurement items of social capital referred to the research by Tsai and Ghoshal [19] and Chiu et al. [5] while four SECI modes referred to Schulze \& Hoegl [17]. The measurement items for performance were derived from Lurey \& Raisinghani [9]. Cronbach's alpha for each construct was conducted by SPSS to assess the reliability. All values were higher than 0.7 , indicating the measurement instrument of this study was reliable.

\section{Analysis Result}

To examine the hypotheses, path analysis, one of the most important statistical tools to test a structural model that reflects causal relationships among variables, was applied. Due to the smaller sample size of male and female groups, Partial Least Squares (PLS) was chosen to construct the path coefficients of proposed model. A popular and reliable tool, SmartPLS 2.0, was applied. We separated data of female group $(n=125)$ and male group $(n=162)$, and constructed path analysis individually. The results are shown in Figure 2 and Figure 3. 


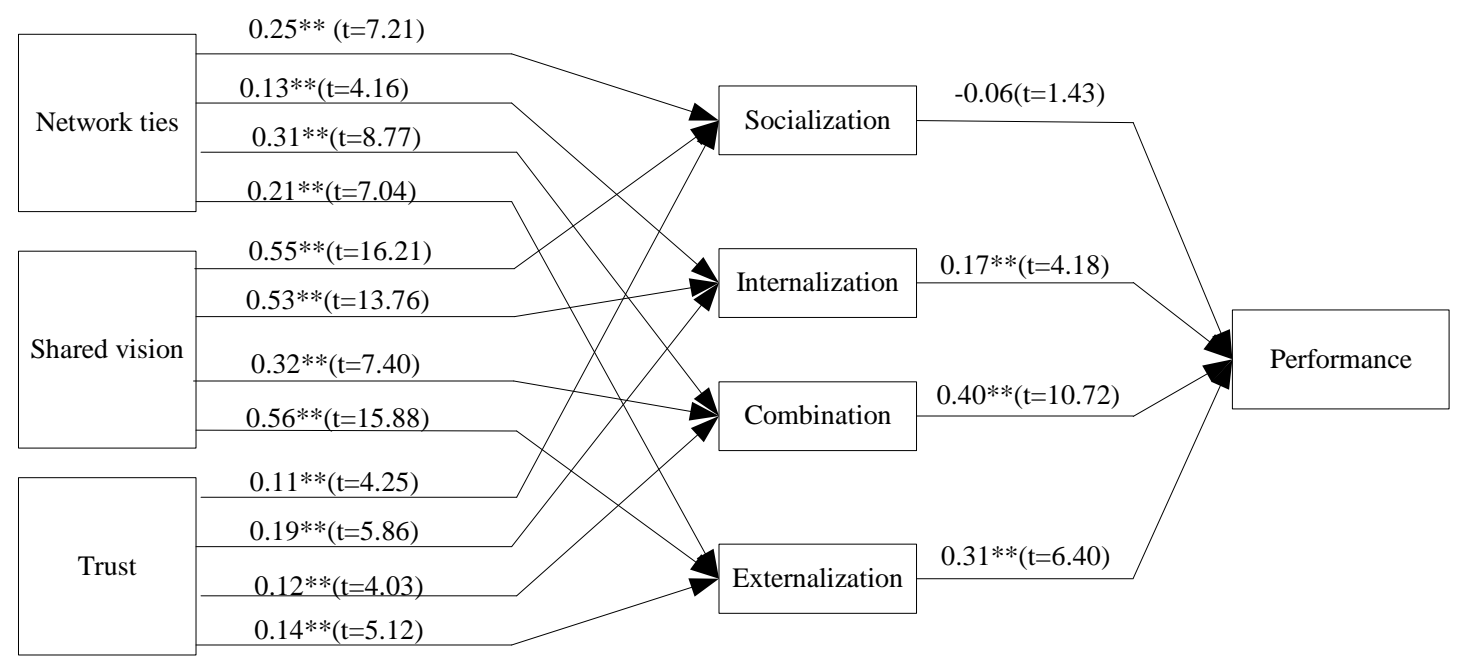

Figure 2. Tested male model

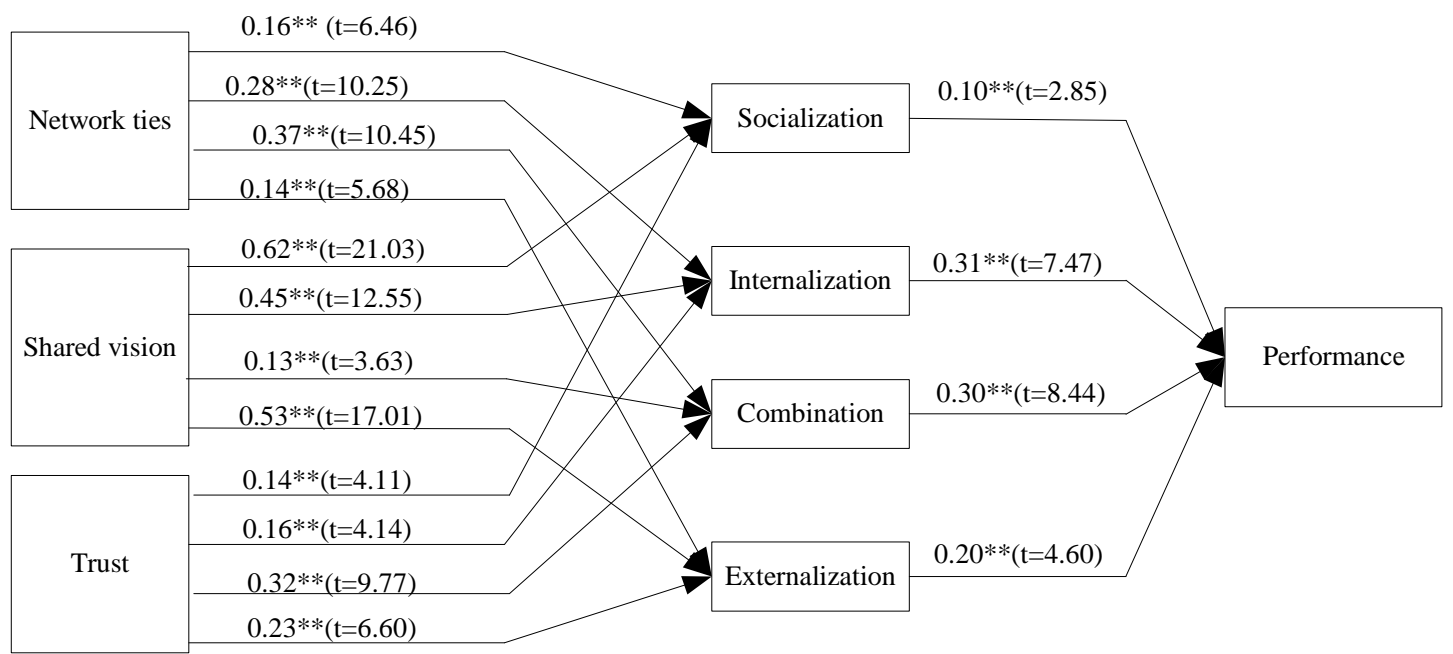

Figure 3. Tested female model

By observing Figure 2 and 3, it can be found that social capital factors (trust, shared vision and trust) have significant impacts on knowledge sharing behaviors (socialization, internalization, combination and externalization), and knowledge sharing behaviors have significant impacts on performance for both genders, except the insignificant path from socialization to performance in male group. Also, the only difference across genders is the insignificant path in male group while it is significant in female group. According to the path coefficients from social capital factors to knowledge sharing behaviors across both models, each paired coefficients have similar strength. Furthermore, the path coefficients from knowledge sharing behaviors to performance across both models also have alike strengths. Therefore, we can conclude that females and males have similar pattern of knowledge sharing behaviors in a perspective of social capital, which partially support our hypothesis.

\section{Conclusions}

This study examined the gender differences in terms of social capital and SECI model, and how they affect virtual team performance. The only difference across genders was the significant path from socialization to performance for female groups. Since socialization refers to the transformation of tacit knowledge, this result implied that females emphasize knowledge assimilation more than males. Knowledge assimilation is derived from social assimilation which is a social process mapping new concepts from others to individuals' ideas. Moreover, females prefer a better team ambiance of knowledge sharing, such as harmonious team atmosphere, well communication and enthusiasm to help others. 


\section{Limitation}

In our analysis, we used PLS to depict casual models for both genders to present an intact view how social capital influences knowledge sharing behaviors and in turn virtual team performance, instead of applying t-test to compare the different perceptions of each constructs across genders. Knowledge sharing is a complex and successive process. If we regard each constructs as isolated factors and compared males and females' perceptions of each constructs, we would obtain rich statistical findings. However, these isolated findings do not provide us further understanding of complex knowledge sharing behaviors. We believe that discussing the patterns which are formed by the path coefficients is more realistic and practical to explore the different behavioral models for both genders.

However, scholars need to be cautious of using the findings of this study. Firstly, due to the imbalance male and female student amounts, we built up groups with pure male and female group and mix-gender group, but constructed models by separating males and females. Thus, the tested model only presented in individual view instead of group level. In addition, the different compositions of the three kinds of groups may affect the interactions between virtual team members, which were not considered in the models. Finally, the measurement items of performance used in this study were regarded as self-rated group performance instead of actual group performance. The reason is that the analytic unit of this study is individual level instead of group level.

\section{References}

[1] P. L. Berger, and T. Luckmann, The social construction of reality: A treatise in the sociology of knowledge, New York: Doubleday, 1966.

[2] D. Byrne, The attraction paradigm, New York: Academic Press, 1971.

[3] R. J. Calantonea, T. Cavusgila, and Y. Zhaob, "Learning orientation, firm innovation capability, and firm performance”, Industrial Marketing Management 31, 31(6), pp. 515-524, 2002.

[4] C.-J. Chen, "The effects of knowledge attribute, alliance characteristics, and absorptive capacity on knowledge transfer performance”, $R \& D$ Management, 34(3), pp. 311-321, 2004.

[5] C.-M. Chiu, M.-H. Hsu and E. T. G. Wang, "Understanding knowledge sharing in virtual communities: An integration of social capital and social cognitive theories”, Decision Support Systems, 42(3), pp. 1872-1888, 2006.
[6] D. Gefen, and D. Straub, "Gender differences in the perception and use of email: an extension to the technology acceptance model”, MIS Quarterly, 21(4), pp. 389-401, 1997.

[7] P. Hendriks, "Why share knowledge? The influence of ICT on the motivation for knowledge sharing", Knowledge and Process Management, 6(2), pp. 91-100, 1999.

[8] M. R. Lind, “An exploration of communication channel usage by gender”, Work Study, 50(6), pp. 234-240, 2001.

[9] J. S. Lurey and M. S. Raisinghani, "An empirical study of best practices in virtual teams", Information and Management, 38(8), pp. 523-544, 2001.

[10] R. A. Meyers, D. E. Brashers, L. Winston and L. Grob, "Sex differences and group argument: A theoretical framework and empirical investigation”, Communication Studies, 48(1), pp. 19-41, 1997.

[11] E. W. Morrison, "Newcomers' relationships: The role of social network ties during socialization", Academy of Management Journal, 45(6), pp. 1149-1160, 2002.

[12] J. Nahapiet and S. Ghoshal, "Social capital, intellectual capital, and the organizational advantage", Academy of Management Review, 23(2), pp. 242-266, 1998.

[13] I. Nonaka, "A dynamic theory of organizational knowledge creation”, Organization Science, 5(1), pp. 1437, 1994.

[14] B. O'Farrell and S. Harlan, "Craftworkers and clerks: The effect of male coworker hostility on women's satisfaction with nontraditional jobs”, Social Problems, 29(3), pp. 252-264, 1982.

[15] J. D. Politis, "The connection between trust and knowledge management: what are its implications for team performance", Journal of Knowledge Management, 7(5), pp. 55-66, 2003.

[16] G. Probst, S. Raub and K. Romhardt, Managing knowledge: building blocks for success, Chicheste: John Wiley \& Sons Ltd, 2000.

[17] A. Schulze and M. Hoegl, "Organizational knowledge creation and the generation of new product ideas: A behavioral approach", Research Policy, 37(10), pp. 17421750, 2008.

[18] M. Z. Sheu, and W.-C. Wong, "A knowledge assimilation schema for acquiring technical knowledge”, Journal of Information Systems Education, retrieve from http://findarticles.com/p/articles/mi_qa4041/is_200607/ai_ n16608735/, 2006.

[19] W. Tsai and S. Ghoshal, "Social capital and value creation: The role of intrafirm networks", Academy of Management Journal, 41(4), pp. 464-476, 1998.

[20] A. Tsui, T. Egan and C. A. O'Reilly, "Being different: Relational demography and organizational attachment”, 
Administrative Science Quarterly, 37(4), pp. 549-579, 1992.

[21] J. Wajcman, Feminism confronts technology. University Park, PA: The Pennsylvania University Press, 1991.

[22] M. M. Wasko and S. Faraj, "Why Should I Share? Examining Social Capital and Knowledge Contribution in Electronic Networks of Practice”, Management Information Systems Quarterly, 29(1), pp. 35-57, 2005.

[23] K. Y. Williams and C. A. O'Reilly, 'The complexity of diversity: A review of forty years of research', in B. Staw and R. Sutton (Eds.), Research in Organizational Behavior, Greenwich, GT: JAI Press, vol. 21, pp. 77$140,1998$.

[24] H. Yli-Renko, E. Autio and H. J. Sapienza, "Social capital, knowledge acquisition, and knowledge exploitation in young technology-based firms", Strategic Management Journal, 22(6), pp. 587-613, 2001. 